\title{
APRECIAÇÃO GEOLÓGICA E PETROGRÁFICA DE ALGUMAS ROCHAS BĀSICAS DE SANTOS
}

\author{
ERnesto Pichler e JoÃo Ernesto de Souza Campos \\ (Da Universidade de São Paulo)
}

\begin{abstract}
In the present paper the authors present some data on the geology of Santos considering particularly the occurrences of basic rocks. The geologic map shows the main occurrences of these rocks, indicating their respective geologic coordinates. A rather detailed petrographic study of rocks, sampled at the occurences of São Vicente and ilha Porchat, revealed that the first one was a lamprophyric dike with a high percentage of olivine whereas the rock of the ilha Porchat was classified as diabase. It is the opinion of the authors that these occurrences originated at different geologic times, and that the olivinic rocks of Săo Vicente, whose origin is likely to be connected with the epeirogenic movements of the serra do mar, are younger than the diabase of the ilha Porchat.
\end{abstract}

\section{INTRODUÇÃO}

$\mathrm{Na}$ estrutura geológica e petrográfica de Santos e arredores imediatos destacam-se três formações diversas. A formação précambriana, constituida por xistos, gnaisses e granitos; a quaternária, constituida de areias e argilas de fácies marinho e intrusivas básicas diversas, cortando as rochas cristalinas do pré-cambriano. Baseado no reconhecimento dos afloramentos observados, foi desenhado o mapa geológico da região, indicando a distribuição das diversas formações mencionadas e em particular algumas dias ocorrências das rochas básicas.

\section{FORMAÇÕES PRE-CAMBRIANAS}

Admite-se, de modo geral, ser a região de Santos constituida de rochas cristalinas pré-cambrianas, xistos, gnaisses, e granitos que, qual ilhas afloram na planície quaternária. Logo na entrada de Santos, sofre a estrada de rodagem São Paulo-Santos, perto do cemitério do Saboó, um estrangulamento no morro de São Bento, notando-se ser a rocha constituida de gnaisse granitizado. Mais adiante, quando se passa para o morro do Fontana, observa-se, encaixados no gnaisse e concordantes com êle, diversas zonas de biotita xisto, cuja largura ultrapassa um metro. No próprio morro do Fontana depara-se, logo na sua base, uma pedreira abandonada. Consiste a rocha aí de gnaisse granitizado, observando-se também faixas de xisto, assim como pegmatitos. Conforme se verifica no mapa geológico, estendeu-se a formação cristalina dos morros em di- 
reção nordeste, passando pela bacia de São Vicente. E interessante notar que a rocha que aflora nas pedreiras de São Vicente, no morro de Voturuá, é um granito de textura fina, coloração predominante cinza, aparecendo porém, algumas faixas de coloração creme. Na Ilha Porchat novamente reaparece o gnaisse. Apresenta êste, aí, xistosidade mais pronunciada que a observada do lado da entrada de Santos. São mais frequentes aqui também as faixas de xisto. Este xisto é do mesmo tipo que o observado no morro de São Bento, ocorrendo porém, aí, com mais frequência, mas com menor possança.

\section{FORMAÇÃO QUATERNÁRIA}

A formação quaternária, que na extensão do mapa geológico é de fácies marinho, consiste de argilas siltosas com matéria orgânica e areias finas que se estendem numa sequência alternada, à profundidade superior a 50 metros.

\section{OCORRENCIAS DE INTRUSIVAS BÁSICAS}

Ocorrências de rochas intrusivas básicas, objetivo principal dêste trabalho, foram registradas em três lugares:

a) - na pedreira de São Vicente;

b) - na Ilha Porchat e

c) - no tunel rodoviário que atravessa o morro do Fontana.

Neste trabalho procurar-se-á estudar as duas primeiras ocorrências. As intrusivas que atravessam o morro do Fontana no tunel rodoviário serão objeto de um outro estudo.

a) - A ocorrência na pedreira de São Vicente consiste de três diques que aí atravessam o granito. O dique principal tem espessura de cêrca $30 \mathrm{~cm}$ e atravessa a rocha encaixante $e_{r}$ segundo a direção $\mathrm{N} 70^{\circ} \mathrm{E}$, tend'o mergulho pràticamente normal. Dado o estado de alteração pronunciada da rocha intrusiva na superfície e sendo parcialmente coberto pelos detritos da pedreira, fàcilmente escapa à observação. A fotografia n. ${ }^{\circ} 1$ apresenta um aspecto dêste dique.

A uma distância de aproximadamente 100 metros dois diques menores, paralelos ao primeiro, foram registrados. Têm êles espessura de não mais de $10 \mathrm{~cm}$, sendo a rocha muito menos alterada que o dique maior.

b) - A segunda ocorrência de rochas básicas observada é a da ilha Porchat. E esta sem dúvida, a ocorrência mais importante de tôdas as que foram observadas. A fata- 
grafia n. 2 apresenta um aspecto dêste dique. A rocha encaixante é um gnaisse que apresenta xistosidade pronunciada, observando-se mesmo zonas de biotita xisto pura (fotografia n. ${ }^{\circ} 3$ ). Encontra-se aquí ainda extensos veieiros de pegmatitos como o mostra a mesma fotografia. A direção do gnaisse varia de $\mathbf{N} 14^{\circ} \mathrm{W}$ a $\mathbf{N} 34^{\circ} \mathrm{W}$ sendo o mergulho pràticamente sempre normal.

O dique de rocha básica atravessa o gnaisse quase normalmente. A sua direção ao longo da face de contacto com o gnaisse é de $\mathbf{N} 30^{\circ} \mathrm{E}$ com mergulho normal, ou pouco inclinado para fora. Nota-se que o dique teve inicialmente espessura de 15 metros mais ou menos, sendo erodida no correr do tempo parte do mesmo, de maneira a formar um vale estreito, tendo do lado oeste o antigo paredāo de contacto gnaíssico e do lado leste a escarpa formada pelo dique cuja espessura atual é reduzida a $8 \mathrm{~m}$ aproximadamente. Não se figura impossível a idéia de uma fratura tectônica ou falha ao longo do plano de contacto do dique com o gnaisse encaixante. Confcrme se observa nas fotografias n. 4 e 5 , apresenta o dique certa disjunção colunar, com o eixo longitudinal principal pràticamente normal a face do contacto leste, face que pode também ser vista nessas fotos.

c) - Considerando a modalidade de apresentação das rochas descritas, assim como o seu respectivo caráter petrográfico, parece pader concluir-se que se trata de intrusões distintas de idades geológicas bem diversas. O diabásio da ilha Porchat apresenta textura holocristalina das rochas consolidadas em profundidade, ao passo que a rocha dos diques d'a pedreira de São Vicente mostra ter cristalizadio próximo a superfície, ccino o indicam as amígdalas abundantes que contém. Tanto a primeira como a segunda variedade de intrusivas básicas, devem ter a sua origem ligadas aos movimentos epeirogênicos, que tiveram lugar no fim do terciário cu no começo do quaternário. Possível admitir, ser o diabásio da ilha Porchat, que apresenta características petrográficas semelhantes à rocha que se encontra numa pedreira localizada ao lado da Via Anchieta, logo no início da descida da serra, geològicamente mais antigo que as intrusivas de São Vicente. Não é permitido entretanto em face dos elementos de que se dispc̃e ser muito positivo a respeito.

Em face da modalidade de apresentação das diversas ocorrências mencionadas, que sugeriram a conveniência de um melhor conhecimen- 
to dos mesmos, julgou-se justificada uma amostragem completa nas mesmas para efeito do respectivo estudo petrográfico.

\section{ESTUDO PETROGRÁFICO}

Rocha $\mathrm{Pv}$ (a) - dique lamprofírico da pedreira Voturuá (São Vicente)

\section{Exame macroscópico}

Rocha homogênea, compacta, afanítica, de côr cinzenta-esverdeada escura, ultra-melânica, exibindo, às vezes, finas veias e amígdalas preenchidas por material claro. Apresenta fratura conchoidal a plana e superfícies planas delimitando formas prismáticas decorrentes de diaclasamento. Tratada com $\mathrm{HCl}$ dá reação com efervescência não só em sua superfície como especialmente nas vênulas e amígdalas. Pulveriza$\mathrm{da}$, os fragmentos resultantes são fàcilmente atraidos pelo imã. $O$ pó é parcialmente solúvel nos ácidos, com efervescência, resultando solução amarelo-esverdeada muito acentuada que dá reação característica de $\mathbf{F e}$ em presença de KCNS. Pêso específico $=2,994$.

\section{Exame microscópico}

A textura exibida pela rocha é panidiomórfica porfirítica (Fig. 1). Os principais fenocristais encontrados são os de olivina, por vezes idiomorfos, exibindo hábitos prismáticos, clivagem, alteração e reabsorção incipientes (fotomicrog. 1). Alguns fenocristais também de titanoaugita, sendo por vezes zonados (fotomicrog. 2).

No feltro foi possível identificar cristais de biotita, às vezes exibindo faces (001), ripas (microlitos) do piroxênio acima citado e cristais de magnetita, numerosos e de diferentes tamanhos, exibindo, por vezes, hábito octaédrico, identificáveis também pelo comportamento de fragmentos da rocha em presença do imã. Ocorrem também vênulas preenchidas por calcita e amígdalas por calcita e analcita (Fig. 2 e fotomicrog. 3). Em uma das amígdalas (Fotomicrog. 4) em que ocorrem cristais idiomorfos de analcita foi possível confimar-la procedendo a medida, na platina Universal, dos ângulos $211 \Lambda 121=33^{\circ}$ e $211 \Lambda 2 \overline{11}=48^{\circ}$ Outro dado seguro para sua identificação foi verificação de clivagens seg. (100) em alguns exemplares dos cristais das amígdalas. A massa fundamental, isótropa, não foi identificada diretamente em lâminas ao microscópio, mesmo quando em uma delas procurou-se reduzir ao mínimo a espessura $( \pm 15 \mu)$ Para procurar resolver o problema foi um fragmento da rocha finamente pulverizado (peneira $150 \mathrm{mshs}$.) e o pó resultante submetido por centrifugação em bromofôrmio com o objétivo de isolar o material 
siálico encontrado exclusivamente na massa fundamental. $O$ material mais leve, assim separado, filtrado e sêco em estufa, foi submetido aos seguintes ensaios:

a) - exame macrocơpico pelo método da imersão

Alguns dos grânulos examinados mostrando fraca birrefringência, exibiram índices de refração em redor de 1,49 danđo, por conseguinte, a impressão de se tratar de analcita ou de sodalita. Como, entretanto, a pulverização da rocha poderia ter acarretado também a trituração do material que preenche as amígdalas (o que sem dúvida deve ter acontecido, pois foram também identificados muitos grânulos de calcita) e consequentemente da analcita ali presente, não ficou satisfatòriamente resolvido o problema no que concerne a natureza do material da base. Ficou entretanto, de certa maneira, excluída a possibilidade de ser o material da base constituído de substância vítrea pois segundo Grout (1932) esta apresentaria índice superior a 1,56 .

b) tratamento por $\mathrm{HNO}_{3}$, seguido de evaporação lenta

O método preconizado por Winchell (1933) destinou-se a decidir se o material siálico, representado pelos grânulos alguns dos quais exibiram índices de refração em tôrno de 1,49, seria constituído de analcita ou de sodalita. Este último mineral, pelo processo em aprêço daria origem a pequenos cubos de salgema. Tendo a prova sido negativa, concluiu-se que o material em aprêço seria constituído de analcita.

c) aquecimento em tubo aberto

O ensaio revelou a'esprendimento de vapor d'agua que se condensou sob forma de gotículas nas paredes frias do tubo de ensaio.

d) tratamento com $\mathrm{HCl}$

Tratando o pó pelo $\mathrm{HCl}$ dil. 1: 1, verificou-se preliminarmente efervescência, provàvelmente causada pela presença de calcita e posteriormente, após aquecimento mais prolongado, gelatinização.

Tôdas essas provas foram de certa maneira concludentes em relação à presença de analcita no material estudado muito embora não ti- 
vessem o mérito de demonstrar que êste material seria o constituinte da base, podendo muito bem ser, como acima foi dito, resultante do material que preenchia as amígdalas.

Verificou-se, entretanto, a existência de certas peculiaridades muito evidentes particularmente em uma das lâminas estudadas. Essas consistiam na presença de zonas bem diferenciadas, espécies de espaços miarolíticos, de natureza pegmatóide, onde os cristais presentes, encontrađios também no corpo da rocha, especialmente biotita e titanoaugita se desenvolveram mais acentuadamente do que na matriz, como consequência da ação de gazes que teriam emprestado nesses pontos, maior fluidez ao magma. Nessas zonas (Fig. 2 e Fotomicrog. 5) foi verificada a presença, como base, do mesmo material isótropo encontrado nas amígdalas, isto é, de analcita, o que conduziu a hipótese de ser êste mineral o formador da base no próprio corpo da rocha, portanto de origem primária como propõe Lindgreen (1890)

Vale assinalar que no material próximo ao contacto ocorrem variações não só texturais como na composição mineralógica. Além de apresentar-se mais compacta, pràticamente destituída de amígdalas, os fenocristais de olivina exibem nítida serpentinização e carbonatação e os cristais de biotita são raros e pouco desenvolvidios.

Dados mineralógicos quantitativos

A determinação na platina integradora deu os seguintes resultados (aproximadamente):

a) Determinação volumétrica:

1) Fenocristais - $31 \%\left\{\begin{array}{l}17,9 \% \text { de olivina } \\ 13,8 \% \text { de titanoaugita }\end{array}\right.$

Feltro $\quad-68,3 \%$

2) A determinação feita por mineral, incluindo fenocristais e material que preenche as amígdalas, forneceu os seguintes resultados :

$\begin{array}{ll}\text { Olivina } & -15,6 \% \\ \text { Titanoaugita } & -54,9 \% \\ \text { Biotita } & -6,7 \% \\ \text { Minerais siálicos* } & -14,1 \% \\ \text { Magnetita } & -8,5 \%\end{array}$

(* Minerais siálicos compreende: analcita, calcita, apatita.) 
b) Determinação em pêso (resultados globais)

$\begin{array}{llr}\text { Olivina } & -\quad 15,9 \% \\ \text { Titanoaugita } & -\quad 54,2 \% \\ \text { Biotita } & -\quad 5,4 \% \\ \text { Siálicos } & -\quad 10,0 \% \\ \text { Magnetita } & -\quad 13,6 \%\end{array}$

Analise química *

A análise química realizada para fins de contrôle forneceu os seguintes resultados :

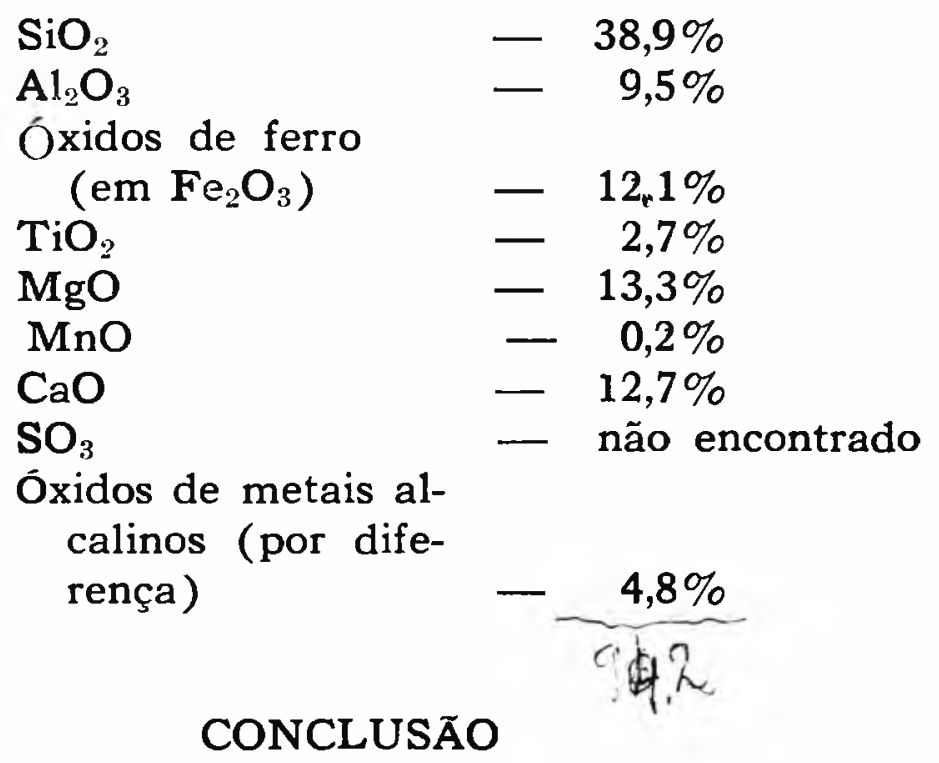

O estudo da literatura sôbre rochas portadoras de olivina e piroxênios de caráter amigdaloidal, hipoabissal, leva à conclusão que a rocha em estudo pode ser considerada um termo da família $3125 \mathrm{E}$, segundo Johannsen (1938) ou mais pròximamente do tipo ankaratrítico-analcítico. A admissão de se tratar de um ankaratríto, Lacroix (1916) ou melhor de uma variedade limburgitica dessa rocha resultou da quase perfeita identidade no que concerne à composição mineralógica como da semelhança entre as análises químicas (vol. 3 - pag. 365 - tabela 131-7). A presença de amígdalas preenchidas por analcita e calcita põe em evidência a solidificação próxima à superfície, embora a rocha ocorra sob forma de dique. Rochas semelhantes foram também estưuadas por L. V. Pirsson (1905) sob a designação de monchiquose (analcita-basalto).

(*) Analista: I. P T. 
Rocha Pv (b) - do pequeno dique lamprofírico da pedreira Voturuá.

\section{Exame macroscópico}

Rocha homogênea, mais compacta do que a acima descrita, de côr cinza escura bem esverdeada, ultramelânica, desprovida de amígdalas visíveis com auxílio de lupa e cortada por algumas veias finas preenchicias por material claro. Fratura conchoidal a plana. Superfícies planas. delimitando formas prismáticas por diaclase. Tratada com $\mathrm{HCl}$ dá reação de efervescência em vários pontos de sua superfície, especialmente onde ocorrem veias e depósitos secundários de calcita. $\mathrm{O}$ pó resultante da trituração é também, como na rocha anteriormente estudada, fàcilmente atraido pelo imã. $\mathrm{O}$ pó tratado pelo $\mathrm{HCl}$ é soluvel com alguma efervecência e a solução amarelo-esverdeada dá reação característica para o Fe em presença do KCNS. Pêso específico: 2,874.

Exame microscópico

A textura é também panidiomórfica porfirítica, exibindo os microcristais do feltro nítida orientação fluidal (Fig. 3). Os fenocristais de olivina muito bem formados e numerosos, exibem hábitos prismáticos e alteração em antigor ${ }^{i} t a$, carbonatos e magnetita, sendo pouquíssimos os cristais parcialmente preservados. Os fenocristais de piroxêno aegirina-augita, apresentam-se por vezes geminados e geralmente bem formados. Numa das lâminas observou-se um fenocristal de aegirina-augita, parcialmente alterado em serpentina e exibindo núcleo de piroxênio rômbicoenstatita (Fig. 4) No feltro predominam as ripas muito finas de aegirina-augita, sendo pequena ou quase nula a presença de biotita. Numerosíssimos são os cristais de magnetita, que mostram, às vezes, hábito octaédrico. A base, como na rocha anterior, é constituida de analcita a qual é também observada em espaços amigdalóidais no corpo da rocha. A fotomicrog. 6 exibe também uma zona diferenciada do tipo miarolítico em tudo semelhante ao descrito na rocha anterior

\section{Dados mineralógicos quantitativos}

Na platina integradora foram determinados os seguintes valores. volumétricos (aproximados):

Olivina (fenocristais) $9 \%$

Aegirina-augita (fenocristais)

$10 \%$

Feltro (pirox. + magnt. + analcita)* $80 \%$

Amígdalas (espaços amigdaloidais) $1 \%$

(* A textura extremamente fina do feltro não permitiu a contagem isoladamente dos minerais que o constituem).

Os fenocristais de olivina variam entre média de 20 a $500 \mu$ aegirina-augita " " 10 a $20 \mu$ 
Análise química

A análise química realizada para fins de controle, forneceu os seguintes resultados:

$\mathrm{SiO}_{2}$

$\mathrm{Al}_{2} \mathrm{O}^{3}$

Óxidos de ferro (em

$$
\mathrm{Fe}_{2} \mathrm{O}^{2}
$$

$\mathrm{TiO}_{2}$

Cao

$\mathrm{MnO}$

$\mathrm{SO}^{3}$

Óxidos de metais alca-
$38,2 \%$

$10,6 \%$

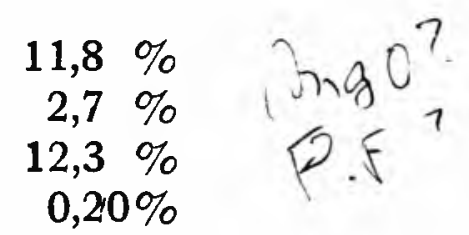

não encontrado

linos (por diferença)

$2,6 \%$

18.4

Conclusão: Apesar das diferenças texturais, da anâlise química e de composição mineralógica - natureza do piroxênio, ausência quase completa de biotita - foi a rocha considerada equivalente à anteriormente descrita.

As rochas dos diques lamprofíricos aqui estudadas e que foram consideradas como uma variedade limburgítica de um analcita ankaratrito, encontram-se de fato constituido têrmos intermediárics entre as famílias dos piroxênitos e dos peridotitos cujos têrmos ankaratrítico de um lado e picrítico de outro apresentam alguns pontos de cortactos e outros de divergência. São entretanto ligadas por seu aspecto geral e composição mineralógica de certa maneira aos jacupiranguitos de cujo magma podem derivar ou mostrar relações de consangüinidade. Othon Leonardos (1941) descreve no rio Batatal dique limburgítico cortando filitos cloríticos. Rochas também semelhantes cuja composição mineralógica é em tudo semelhante a aqui descrita são assinaladas também em Fernando Noronha por Campbell e Burri (1933)

Tentando uma classificação dessas rochas, segundo Tröger (1935), vimos que apresentam várias relações com ankaratritos, Lacroix da família dos ijolitos; limburgitos, Rosembuch, da família dos exessitos; jacupiranguitos, Derby e bebedouritos, Tröger, da família dos piroxenitos.

Rocha Ip-dique da Ilha Porchat (São Vicente)

Exame macroscópico

Rocha homogênea, compacta, fanerítica, de côr cinzenta-escura, melanocrática, apresentando fratura sub-conchoidal a plana. Formas prismáticas de secção hexagonal decorrem dos planos de diaclasamento. Não há efervescência exceptov como é obvio, nos pontos onde se 
deposita calcita secundária e fàcilmente reconhecível a olho nú. Pulverizada, são os fragmentos resultantes atraidos pelo imã. $O$ pó é parcialmente solúvel nos ácidos, com ligeira efervescência, resultando, especialmente após aquecimento, solução amarelo-esverdeada que dá reação característica para o $\mathrm{Fe}$ em presença de KCNS. Pêso específico $=2,975$.

\section{Exame microscópico}

A textura exibida pela rocha é ofítica apresentando regióes, onde se aglomeram piroxênios, tenỏendo a granular. Os cristais ripiformes de plagioclásio são constituídos de labradorita e o piroxênio, por vezes idiomorfo, às vezes exibindo geminações, é constituído de augita. O mineral metálico é formado por magnetita o que é identificável pedo hábito e pelo comportamento de fragmentos da rocha em presença do imã. Encontra-se também alguma ilmenita parcialmente alterada em leucoxênio (Fig. 5 e fotomicrografia 8) Numa das lâminas estudadas foi observada estrutura reticulada resultante de pseudomorfose de antigorita sôbre um cristal provávelmente de olivina (?), como pode ser observada na Fig. 6. A suposição de se tratar de olivina decorre do fato de se encontrar grânulos de magnetita demarcando as linhas de clivagem e de fratura-Dana (1950)

Dados mineralógicos quantitativos:

$\mathrm{Na}$ platina integradora foram obtidos os seguintes resultados aproximados (em pêso):

$\begin{array}{lr}\text { Labradorita } & 41 \% \\ \text { Augita } & 29 \% \\ \text { Magnetita } & 7 \% \\ \text { Minerais alterados } & 22 \%\end{array}$

Conclusão: Por sua composição mineralógica, textura e ocorrência $\mathrm{em}$ dique pode ser a rocha considerada como um diabásio.

\section{CONCLUSÕES GERAIS}

1) Não existem dados que permitam afirmar que o diabásio encaixado no gnaisse da ilha Porchat seja anterior ou posterior aos considerados réticos e comuns no planalto do Brasil Meridional.

2) Embora os diques de diabásio e os lamprofiritos descritos estejam próximos e no mesmo nível julgamos que tiveram êles origem em épocas diferentes. 
3) A textura ofítica do diabásio e sua espessura, $15 \mathrm{~m}$ e a ausência de olivina são outros indícios que parecem confirmar o que ficou dito acima.

4) A estrutura dos diques lamprofíricos-porfirítica amigdaloidal sugerem terem êles se formado pràticamente na superfície e como tal ligados a uma manifestação vulcânica anterior ou posterior ao rético.

5) Considerando o granito da pedreira de Voturuá, encaixado $\mathrm{cm}$ gnaisses de idade pré-devoniana, os diques seriam òbviamente posteriores ou contemporâneos a êle.

6) Outras evidências entretanto não existem no que concerne as idades das rochas consideradas.

\section{AGRADECIMENTOS}

Somos gratos aos professores Viktor Leinz e Rui Ribeiro Franco, assim como ao colega Dr. José Moacyr Vianna Coutinho pelas valiosas sugestões e orientação nos trabalhos petrográficos; ao snr. Diocleciano Soares Araujo pela confecção das lâminas e ao snr. G. Oscar Campiglia. da Divisão de Documentação dảa Reitoria pelas fotografias e fotomicrografias que ilustram o presente trabalho.

\section{BIBLIOGRAFIA}

GROUT, F F (1932), Petrography and Petrology - McGraw Hill Company Inc., New York, N. Y

WINCHELL, A. N., (1933), Elements of optical Mineralogy: An introduction to microscopic Petrography: John Wiley and Sons, Inc., New York, London.

LINDGREEN, W (1892), Eruptive rocks from Montana: Proc. California Acad. Sci. Ser 2, vol. III, 1890, p. 51.

JOHANNSEN, A., (1938), A descriptive petrography of the igneous rocks: vol. IV - The University of Chicago Press. Chicago, Illinois, USA.

LACROIX, A., (1916), La constitution des roches vulcaniques de l'extreme nord de Madagascar et de Nosy bé; les ankaratrites de Madagascat en general; Comp. Rend., CLXIII, 1916. pp. 256-358.

PIRSSON, L. V., (1905), Petrography and Geology of the igneous rocks of the Highwood Moutains, Montana: U.S.G.S. Bull., 237, 1905, pp. 149-158. 
DANA, E. S., (1950), Text-Book of Mineralogy: IV edition. John Wiley \& Sons, Inc. New York, USA.

LEONARDOS, O. H. (1941), Notas petrográficas sôbre a série Ribeira: Mineralogia n. ${ }^{\circ}$, Bol. Fac. Fil. Ci. Letras n..$^{\circ}$ XI, USP p. 10.

CAMPBELL, S. W e BURRI, C. (1933), The igneous rocks of Fernando Noronha: Bol. Suisse e Min. e Petrog., vol XVII.

TRÖGER, W. E. (1935), Spezielle Petrographie der Eruptivegesteine: Berlin W 35 Vertag der Rentschen Mineralogischen Gesselchafte V

ESKOLA, P (1954), Ein Lamprophyrgang in Helsinki und die Lamprophyr probleme: Tscherm. Min und Petrog. Mitt. vol. 4. 